\title{
GESTÃO DA INFORMALIDADE URBANA E TOLERÂNCIA PRECÁRIA: UMA REFLEXÃO CRÍTICA EM TORNO DOS SENTIDOS IMPLICADOS EM PROJETOS DE REGULARIZAÇÃO FUNDIÁRIA
}

\author{
Rafael Soares Gonçalves* \\ Caroline Rocha dos Santos** \\ * Pontifícia Universidade Católica do Rio de Janeiro, Departamento de Serviço Social, Rio de Janeiro, RJ, Brasil \\ ** Universidade do Estado do Rio de Janeiro, Programa de Pós-graduação em Direito e Centro Universitário \\ Gama e Souza, Departamento de Direito, Rio de Janeiro, RJ, Brasil
}

\begin{abstract}
Resumo
Durante os anos de 2015 e 2016, estivemos envolvidos em projetos de regularização urbanística e fundiária destinados às localidades identificadas como Conjunto Habitacional Carlos Gomes e Hípica, situadas, respectivamente, nos bairros de Barretos e Charitas na cidade de Niterói, zona metropolitana do estado do Rio de Janeiro. O presente artigo é um esforço de organização e reflexão crítica sobre essa experiência com o intuito de perceber em que medida tais projetos rompem ou reforçam o paradigma que vem caracterizando a relação entre Estado e áreas de moradia ocupadas pela população pauperizada. Para realizar essa análise, debruçamo-nos sobre informações a respeito dos aspectos gerais do Programa Papel Passado e sobre dados específicos acerca de sua implementação nas localidades em que atuamos.

Palavras-chave

Regularização Fundiária; Programa Papel Passado; Direito à Cidade; Informalidade.
\end{abstract}




\title{
GOVERNANCE OF URBAN INFORMALITY AND \\ PRECARIOUS TOLERANCE: A CRITICAL REFLECTION \\ AROUND THE MEANINGS INVOLVED IN LAND REGULARIZATION PROJECTS
}

\author{
Rafael Soares Gonçalves* \\ Caroline Rocha dos Santos ${ }^{* *}$ \\ * Pontifícia Universidade Católica do Rio de Janeiro, Departamento de Serviço Social, Rio de Janeiro, RJ, Brazil \\ ** Universidade do Estado do Rio de Janeiro, Programa de Pós-graduação em Direito e Centro Universitário \\ Gama e Souza, Departamento de Direito, Rio de Janeiro, RJ, Brazil
}

\begin{abstract}
From 2015 to 2016, we were involved in urban and land tenure regularization projects addressed to a housing estate, called Carlos Gomes, and a favela named Hipica, located, respectively, in the neighborhoods of Barretos and Charitas in the city of Niterói, in the metropolitan area of Rio de Janeiro. This article aims to reflect on this experience in order to understand if these projects break or reinforce the paradigm that has marked the relationship between the State and squatter settlements. To carry out this analysis, we look at the Programa Papel Passado and the way how it happened in the locations where we operated.

Keywords

Land Regularization; Programa Papel Passado; Right to the City; Informality.
\end{abstract}




\section{GESTÃO DA INFORMALIDADE URBANA E TOLERÂNCIA PRECÁRIA: UMA REFLEXÃO CRÍTICA EM TORNO DOS SENTIDOS IMPLICADOS EM PROJETOS DE REGULARIZAÇÃO FUNDIÁRIA'}

Rafael Soares Gonçalves

Caroline Rocha dos Santos

Introdução

Durante os anos de 2015 e 2016, participamos, como advogados, de projetos de regularização urbanística e fundiária, desenvolvidos a princípio no âmbito do Programa Papel Passado, para as localidades identificadas como Conjunto Habitacional Carlos Gomes e Hípica, situadas, respectivamente, nos bairros de Barretos e Charitas, na cidade de Niterói².

A Região Metropolitana do Rio de Janeiro, da qual faz parte esse município, tem se configurado, ao menos desde a década de 1960, como um importante espaço no qual se acumularam intervenções estatais de regularização fundiária voltadas à moradia de população de baixa renda e, em especial, às favelas. Se, por um lado, os distintos sentidos e temporalidades com base nos quais cada uma dessas ações foi concebida nos impedem de olhar para esse histórico como algo linear e homogêneo, por outro, é possível afirmar, com o apoio de ampla bibliografia sobre o tema, que a dificuldade de finalizar as etapas necessárias à regularização fundiária é um dado em comum entre a maior parte dos referidos programas (COPANS, 2003; BIENENSTEIN et al., 2017; JAENISCH; XIMENES, 2019; GUERREIRO; ROLNIK, 2020).

Neste sentido, sem a pretensão de universalizar qualquer uma de nossas reflexões, assumimos um caminho metodológico que não opera com a tradicional

\footnotetext{
1. As reflexões que aprofundamos neste artigo foram inicialmente apresentadas no III Seminário Nacional de Urbanização de Favelas, ocorrido em Salvador (BA) no ano de 2018.

2. Neste trabalho, utilizamos a nomenclatura das localidades conforme o uso feito pela Prefeitura de Niterói ao inseri-las no Programa Papel Passado.
} 
divisão entre objetivos, problemas e hipóteses. De forma distinta, tomamos as intervenções ocorridas no Conjunto Habitacional Carlos Gomes e em Hípica como casos que, em razão de sua singularidade, são pertinentes para pensar essa recorrente inconclusão enquanto manifestação de um modo de gestão específico dos espaços de moradia da população de baixa renda, mais especificamente das favelas (MACHADO DA SILVA, 2010)3, aqui entendido por meio do conceito que denominamos "tolerância precária” (GONÇALVES, 2013).

Por ora, já antecipamos que essa gestão se caracteriza pela dinâmica de suspensão e aplicação, para tais territórios, de um status de ilegalidade/informalidade/irregularidade a partir do qual se perpetua a condição de insegurança da posse dessas ocupações, fazendo com que sua permanência dependa constantemente de arranjos pontuais que, em geral, enfrentam dificuldades para se consolidar ao longo do tempo.

Para compreender essa engrenagem, mobilizamos a leitura conjunta de Nezar Alsayyad (2004), Ananya Roy (2009), além de Veena Das e Deborah Poole (2004), segundo os quais a gestão das fronteiras que definem o legal e o ilegal, o informal e o formal, o irregular e o regular revela, em si, o próprio exercício do poder soberano. Se Alsayyad (2004) utiliza o termo informalidade urbana para indicar uma lógica organizacional, um sistema de normas de regulação dos processos de transformação urbana, inclusive dialogando com práticas neoliberais, Roy (2009), por sua vez, evoca um regime informal urbano, em que o Estado utiliza ativamente a informalidade como um instrumento de acumulação e autoridade, coadunando, assim, com o pensamento de Veena Das e Deborah Poole (2004), de acordo com o qual o Estado se produz ao produzir suas margens.

Essa fundamentação nos leva a concluir que as tradicionais esferas estatais (instituições e órgãos pertencentes à administração direta e indireta da União, dos estados e municípios, por exemplo) estão implicadas na produção da informalidade na medida em que exercem um papel fundamental na permanente suspensão e aplicação das fronteiras que definem o formal e o informal, ou seja, é o caráter performativo da norma estatal que gera paradoxalmente o que ela não cobre (MACHADO DA SILVA, 2013). Todavia, esse ato de soberania não se concretiza apenas por intermédio dessas instâncias, pois há uma gama de outros vetores, como o mercado imobiliário, que, no espaço e no tempo, se amalgamam na produção e no funcionamento desse dispositivo.

3. A escolha desse caminho metodológico, que opera reflexões mais amplas baseadas na singularidade de um caso, foi inspirada na leitura que Luiz Antônio Machado da Silva (2010) faz de Clifford Geertz. 
Nós levamos em consideração essa advertência, porém, neste artigo, não nos propusemos inventariar todos os interesses, arranjos e agentes que, junto às esferas estatais, mobilizaram as fronteiras entre a formalidade e a informalidade naquele contexto específico no qual atuamos. Neste sentido, destacamos que a descrição dos casos aqui não pretendeu traduzir em um "empírico" a complexidade existente no "real" (FALBO, 2011) 4 e ocorreu como resultado de um recorte por meio do qual olhamos tanto para as diretrizes do Programa Papel Passado, formuladas pela Secretaria Nacional de Acessibilidade e Programas Urbanos, ligada ao extinto Ministério das Cidades, como para as particularidades decorrentes da execução do Programa pela Prefeitura de Niterói.

O corpus de análise se originou de duas fontes principais: o acesso às informações mais gerais sobre a escolha dos projetos submetidos pela Prefeitura de Niterói ao Programa Papel Passado foi obtido pela consulta ao sítio eletrônico do Ministério das Cidades, aos portais da Transparência e do Sistema de Convênios e Contratos de Repasse do Governo Federal (Sinconv), em conjunção com a bibliografia específica sobre o tema, em especial as publicações produzidas pelo próprio ministério. Quanto às informações mais detalhadas sobre o andamento dos projetos no Conjunto Habitacional Carlos Gomes e na Hípica, em face dos compromissos éticos que assumimos quando neles atuávamos, trabalhamos apenas com os dados com que tivemos contato ao longo da nossa participação, mas que poderiam ser acessados por qualquer pessoa interessada.

Em resumo, reiteramos que a perspectiva pela qual analisamos esse recorte nos leva a rechaçar a compreensão da informalidade como condição natural e intrínseca das favelas (sobretudo em relação à forma de apropriação e ao uso daquela terra urbana) que o Estado precisa erradicar. Buscamos, assim, dar à informalidade um sentido político, a partir do qual se identifica e se problematiza o papel do próprio Estado na sua produção, ao mesmo tempo que consideramos, como será pontuado ao longo do texto, a utilização dessa informalidade como um recurso urbano dos moradores e moradoras de favela (GONÇALVES, 2017).

Será à luz desses argumentos que aprofundaremos a noção de tolerância precária ao longo da primeira seção e apresentaremos, na segunda e na terceira seções, uma descrição abreviada das tentativas de regularização fundiária e urbanística do Conjunto Habitacional Carlos Gomes e de Hípica no âmbito do Programa Papel Passado.

4. Falbo (2011) faz uma análise sobre a necessidade de distinguir o real e o empírico nas pesquisas jurídicas e as reverberações disso em torno da produção do conhecimento sobre o direito. 


\section{Tolerância precária e regularização fundiária}

O conceito de tolerância precária às favelas do Rio de Janeiro por parte do Estado, cunhado por Gonçalves (2013), refere-se à forma específica como os poderes públicos nelas intervêm. Historicamente, tais iniciativas mantiveram o status jurídico ilegal, permitindo, a qualquer momento, a remoção das favelas. Segundo Stephen Conn (1968), os poderes públicos mantiveram essa precariedade fundiária para assinalar que, ao menos juridicamente, elas não deveriam existir. As favelas eram consideradas espaços de exceção, conforme sublinha o célebre jurista Barbosa Lima Sobrinho (1957), ao afirmar que a aplicação de sanções legais não constituiu um obstáculo à multiplicação e expansão delas.

A força simbólica dessa representação não bloqueou necessariamente a expansão física das favelas, mas constituiu, sem dúvida, uma moldura muito estrita que limitou o aparecimento de uma reflexão com vistas a integrá-las plenamente à ordem jurídica em vigor. A tolerância à aplicação da lei acabou se impondo, mas de tal forma que esse processo teria continuamente de ser considerado como exceção à lei, ou seja, a tolerância era sempre vista como um ato discricionário sem a vocação de suscitar direitos. A não aplicação da norma não poderia, de maneira alguma, desencadear um reconhecimento das favelas capaz de gerar, como consequência, algum direito aos seus moradores. Tratava-se, portanto, de manter a legitimidade simbólica da norma, permitindo, contudo, paradoxalmente, sua aplicação de modo arbitrário e seletivo (GONÇALVES, 2013).

Constatamos, assim, que as políticas públicas criadas para lidar com a informalidade demonstram como o Estado, seletivamente e muitas vezes arbitrariamente, classifica, regula, distribui e participa da gestão das fronteiras entre formal e informal. Portanto, é importante ressaltar que o Estado não está ausente desses espaços - muito pelo contrário, em muitos casos, é um dos autores principais no desenvolvimento e na consolidação dessas áreas, como será possível perceber nos casos do Conjunto Habitacional Carlos Gomes e de Hípica, analisados a seguir. Admitem-se mesmo intervenções esporádicas nesses espaços com a condição de que elas não conduzam ao seu reconhecimento.

O informal, segundo Jacquot, Sierra e Tadie (2016), aparece articulado, às vezes mesclado, ao formal, produzindo uma variação de regimes de urbanismo e de configurações sociais que compõem e estruturam a cidade, em função dos níveis de práticas informais ali existentes. Não se trata de "setores" distintos e antagônicos: de um lado o formal e, de outro, o informal. Essa distinção não tem cabimento e não é possível conceber a questão apenas em termos dualistas, senão na maneira na qual é considerada pelas instituições dominantes, por evidentes razões de controle e, em muitos casos, de controle e repressão. São, ao contrário, 
interdependentes e as pretensas fronteiras entre formal e informal aparecem não raro de modo mais fluido e com contornos amplamente variáveis (GONÇALVES; BAUTÈS; MANEIRO, 2018).

Observa-se, portanto, uma espécie de regime urbano que absorve a informalidade como um dispositivo, inserido em uma complexa rede de interesses e atores. Com base nessa compreensão, não é de estranhar, como veremos na próxima seção, que o projeto de regularização aqui analisado, no caso de Carlos Gomes, interveio justamente em um conjunto habitacional construído pela própria prefeitura, mas que não apresentava os atributos necessários para alcançar a categoria de espaço formal. Daí se constata que os poderes públicos são produtores de informalidade e, inclusive, em grande escala, ou seja, a informalidade não é uma excrescência de nossas cidades - ela é parte de uma lógica envolvida no ato de governar e gerir nossas cidades a ponto de ser necessário que o Estado regularize aquilo que ele mesmo construiu.

De todo modo, é importante ressaltar que a informalidade urbana pode paradoxalmente se configurar também como um recurso dos seus habitantes (GONÇALVES, 2017), pois, se a precariedade jurídica desses espaços pode conduzir à sua estigmatização e à dos sujeitos que neles vivem (SANTOS, 1980), ela também pode permitir o acesso à cidade a uma parte da população que não o teria pelo mercado formal ou por intermédio dos precários programas de habitação social que com frequência, como no caso de Carlos Gomes, reproduzem a própria informalidade.

A informalidade não seria, assim, somente imposta ativamente pelo Estado ou por negligência, mas se configuraria também como um arranjo, em que os diferentes atores calculam o interesse em reproduzir ou não práticas informais. É nesse sentido que podemos pensar que a informalidade se manifesta como dispositivo, compreendido aqui, na definição foucaultiana, como elemento que permite justificar e mascarar práticas ou mesmo reinterpretá-las, exercendo uma função estratégica para justificar os arranjos variáveis dos diferentes atores, inclusive as mudanças de posição e de funções (FOUCAULT, 1998).

A informalidade exerce, portanto, uma função social e pode ser um elemento relevante no acesso aos recursos urbanos. Como destaca Raquel Rolnik (2015, p. 213), não se observa nos últimos anos interesse popular pela regularização fundiária, sobretudo no Rio de Janeiro. Nos casos em que atuamos, percebemos que os arranjos informais paradoxalmente permitiram a presença daquelas moradoras e moradores em espaços situados em áreas mais centrais da cidade.

Nas próximas seções, refletiremos de maneira mais aprofundada sobre a noção de tolerância precária e a produção da informalidade como dispositivo por 
meio dos elementos fornecidos pelas tentativas de regularização fundiária nos casos do Conjunto Habitacional de Carlos Gomes e Hípica.

2. Os projetos de regularização fundiária em Niterói:

o Programa Papel Passado

A criação do Ministério das Cidades, em 2003, materializou o desejo de formular políticas públicas urbanas mediante uma coordenação nacional, conferindo novamente à esfera federal maior responsabilidade na discussão sobre o destino das cidades (MARICATO, 2006). Se a única referência de estratégias nacionais nesse campo vinha do período ditatorial, caracterizadas pelas práticas tecnocratas e antidemocráticas, a Constituição de 1988 e, posteriormente, a Lei nº. 10.257/2001, mais conhecida como o Estatuto da Cidade, imprimiram um novo paradigma para o planejamento urbano, determinando que tais políticas fossem desenhadas tendo em vista a garantia da função social da cidade (ROLNIK, 2007).

Esse marco legal também conferiu maior autonomia e centralidade aos municípios no planejamento territorial urbano, exigindo que a participação da esfera federal ocorresse mais intensamente nas etapas de planejamento, fiscalização e incentivo às ações necessárias para a efetivação das políticas sobre as cidades que passavam a ser desenhadas. Mas, ao mesmo tempo, isso não impediu que a União exercesse expressiva liderança e criasse o primeiro Programa Nacional de Regularização Fundiária, intitulado Papel Passado, considerado ele mesmo precursor, segundo Carpintero (2017), de uma Política Nacional de Regularização Fundiária:

A União, a princípio, entraria nesse processo de maneira auxiliar, visto não ser seu
papel a execução direta da regularização fundiária, salvo em seus imóveis [...]. No
entanto, o volume de imóveis de propriedade da União, as condições históricas
do processo de urbanização, o papel principal que exerce a União na definição
de normas, princípios e diretrizes na federação brasileira, em especial quando se
trata da questão da terra no Brasil, além do seu papel fundamental no financia-
mento da política urbana, deixam claro que essa posição, em tese auxiliar, passa
a ser exercida muitas vezes como de forte liderança, induzindo, viabilizando e até
definindo e executando grandes projetos de regularização, inclusive de regulari-
zação fundiária em seus aspectos urbanísticos e sociais, para além dos jurídicos
(BALBIM, 2010, apud CARPINTERO, 2017, p.102).

O Programa Papel Passado foi formulado em 2003, com o principal objetivo de apoiar a "regularização fundiária de assentamentos precários em áreas urbanas ocupadas por população de baixa renda” (BRASIL, 2004, p. 57). Posteriormente, esse apoio calcou-se em três pilares: a construção de uma articulação institucional buscando a remoção de obstáculos jurídicos e legais à regularização fundiária; a organização de atividades de capacitação técnica para agentes públicos visando à formação e à atualização profissional; e assistência técnica e financeira aos 
estados, municípios e Distrito Federal para a estruturação de ações voltadas à regularização fundiária (CARPINTERO, 2017).

Neste último caso, como veremos mais à frente, o repasse financeiro era feito, sobretudo, por chamadas públicas (editais) nas quais poderiam concorrer órgãos da administração direta ou indireta de estados, municípios e Distrito Federal e também entidades civis sem fins lucrativos ou defensorias públicas (BRASIL, 2013)5.

O Programa Papel Passado admitia, portanto, uma pluralidade de proponentes, entretanto é preciso reconhecer o papel distinto que os municípios, por meio de suas prefeituras, desempenhavam, uma vez que a Constituição de 1988 delegou a esse ente um lugar importante no exercício de uma política urbana mais descentralizada, ainda que tenha atribuído apenas à União e aos estados a responsabilidade pela produção de normas gerais sobre direito urbanístico (ALMEIDA et al., 2017) . $^{6}$ Logo, os municípios não eram apenas um dentre outros proponentes possíveis, o que se explicitou no fato de que a grande maioria dos projetos contemplados pelo Programa Papel Passado foi apresentada por eles.

Os objetivos traçados por esse Programa se firmavam segundo algumas premissas, como a ideia de que a condição informal/irregular/ilegal7 da moradia dos mais pobres seria um empecilho central à integração mais democrática e com maior distribuição de direitos nas cidades. A irregularidade administrativa e patrimonial das favelas e de outros assentamentos populares teria sido o modelo dominante de territorialização dos pobres nas cidades brasileiras, "fazendo com que estes espaços permanecessem sempre dependentes de ações discricionárias do poder público, já que para as formas legais de expressão de pertencimento à cidade, esses assentamentos sequer existiam” (ROLNIK, 2007, p. 7).

Assim, as ações e políticas pensadas pelo Ministério das Cidades por intermédio da Secretaria Nacional de Programas Urbanos (SNPU) para lidar com essa realidade ocorreriam por meio de duas frentes: i) ações "preventivas” capazes de evitar a formação de novos assentamentos precários no país; e ii) ações “curativas”, cujo objetivo seria efetivar a regularização plena dos assentamentos consolidados, realizar o gerenciamento e a remoção de riscos dos assentamentos precários, bem

5. Ao longo do Programa, a maioria esmagadora dos recursos foi distribuída por meio dessas chamadas públicas, porém os proponentes poderiam captá-los também mediante emendas parlamentares ou uma proposta específica feita diretamente pelo proponente, modalidade em que o Ministério das Cidades discricionariamente decidia por um projeto específico sem a realização de concursos (CALDAS; SILVA, 2015).

6. Sobre esse ponto, Almeida et al. (2017) afirmam que, enquanto a União concedeu a si mesma a primazia na produção da política urbana (policy decision making), aos municípios coube sua execução (policy making).

7. Os três termos são utilizados genericamente nos textos aqui analisados como forma de descrever a condição de não conformidade às normas de ocupação do solo, sejam elas urbanísticas, sejam referentes ao domínio. 
como promover o reconhecimento pleno dos direitos às moradias já constituídas nas cidades (ROLNIK, 2007, p. 9).

Corroborando essa leitura, Celso Santos Carvalho (2007, p. 13), diretor de Assuntos Fundiários da SNPU, reiterou a necessidade de "incorporar as milhões de famílias que vivem de forma irregular à cidade legal, não só pelo reconhecimento formal da posse do terreno, mas também pela implantação da infraestrutura e equipamentos urbanos que permitam adequar o assentamento aos padrões urbanísticos e ambientais do restante da cidade”.

Para cumprir seus objetivos, o Programa Papel Passado, por se tratar de ação curativa, passou a integrar os planejamentos orçamentários e contou com uma dotação na Lei Orçamentária Anual (LOA) de 2004. Contudo, isso não significou o repasse regular ao longo dos anos posteriores. Segundo Carpintero (2017), desde a publicação do primeiro edital, em 2004, ocorreram seis processos de seleção de propostas, organizados sem nenhuma regularidade; já em 2008 houve grande contingenciamento e um intervalo de quatro anos (2009-2013) sem a realização de nenhuma seleção.

Com isso, as poucas propostas apresentadas nos anos em que a seleção de projetos não ocorreu foram subsidiadas com recursos oriundos das outras fontes de financiamento do Programa, e mesmo aquelas selecionadas pelos editais não receberam os valores previstos integralmente (CALDAS; SILVA, 2015). Mais à frente, veremos como essa irregularidade de recursos afetou as áreas específicas nas quais atuamos.

Após um período de três anos sem a realização de certames destinados à seleção de projetos para o Programa Papel Passado, a SNPU lança, em outubro de 2013, seu último edital para a alocação de recursos do Orçamento Geral da União $(\mathrm{OGU})^{8}$ destinados à realização de regularização fundiária em áreas urbanas (BRASIL, 2013). Como pontuado anteriormente, na estrutura do programa, competia ao governo federal o apoio técnico e financeiro às ações de regularização fundiária, enquanto aos municípios caberia concorrer pelos recursos, sobretudo com o envio de projetos, conforme os requisitos exigidos nos editais.

A participação se efetivava então pelo preenchimento das chamadas cartas-consulta, por meio das quais eram concedidas informações sobre as áreas candidatas à recepção do programa. Os projetos, para serem habilitados, deveriam contemplar assentamentos irregulares de baixa renda ocupados havia mais de cinco

8. Os recursos destinados ao Programa tiveram previsão orçamentária no Plano Plurianual mediante a rubrica 8.866 do Programa 2.054. 
anos sem oposição, cuja situação ambiental, de risco e jurídica não comprometesse o processo de regularização fundiária9.

A portaria que tornava pública aquela seleção determinava também que as áreas que apresentassem melhores condições para a regularização fundiária, ou que fossem de propriedade da União, ou ainda cujos proponentes fossem titulares do seu domínio teriam prioridade nessa escolha (BRASIL, 2013). Em relação a esses critérios, Carpintero (2017, p. 116; 121) esclarece que eles expressavam a preocupação de que não houvesse fatores capazes de obstruir a regularização, uma vez que, era provável, "os contratos firmados anteriormente teriam sido paralisados ou cancelados devido à existência de impedimentos ou dificuldades desta natureza (como informações incompletas, tempo de ocupação inferior ao determinado pela legislação, situações de risco difíceis de serem revertidas)".

Os demais critérios fundiários requeridos pelo Programa demandavam a inexistência de impedimentos à própria regularização fundiária, ou seja, era necessário que a área estivesse o mais livre e desembaraçada possível para que pudesse ser contemplada.

Até aqui, tentamos expor as premissas e os objetivos do Programa Papel Passado e os requisitos exigidos na seleção dos projetos. Passamos a descrever, na sequência, alguns aspectos da candidatura do município de Niterói e das localidades que concorriam à recepção do Programa.

Com vistas a preencher os pré-requisitos demandados na seleção, a Prefeitura de Niterói submeteu um projeto constituído por cartas-consulta que continham as informações sobre as localidades candidatas à recepção do Programa em foco, quais fossem: Conjunto Habitacional Carlos Gomes, Hípica e Morro Lara Vilela ${ }^{10}$. Essas cartas apresentavam elementos em comum e aqui chamamos atenção para duas semelhanças: i) o destaque na capacidade da prefeitura para realizar ações voltadas à regularização fundiária e ii) a ênfase na ausência de empecilhos à regularização fundiária nas localidades candidatas a participar do Programa.

Assim, a primeira semelhança repousa no esforço da prefeitura em demonstrar a presença de uma estrutura administrativa municipal capaz de executar as ações necessárias à regularização fundiária e urbanística. Porém, como veremos

\footnotetext{
9. Sobre a utilização dos critérios de seleção, Carpintero (2017, p. 116) elucida que eles eram "utilizados pelo MCidades para priorizar a seleção de propostas. O não atendimento a algum critério não leva necessariamente à desclassificação, mas pode resultar em uma pior classificação, que pode contribuir para a não seleção".

10. O Morro Lara Vilela não será escopo de nossa análise porque não participamos das ações de regularização fundiária dessa localidade. Isso não impede, todavia, que informações referentes a ela apareçam indiretamente no texto.
} 
adiante, a existência dessa expertise será posta à prova pela própria dificuldade de conclusão do projeto, ainda que a regularização fundiária e urbanística conste como instrumento necessário à realização da função social da propriedade, tal como determinava o antigo Plano Diretor da cidade de Niterói, em seu. art. 8º, III, alínea “q” (NITERÓI, 1992).

A segunda semelhança, por sua vez, é revelada pelo conjunto de informações que buscavam evidenciar que as áreas candidatas ao Programa já apresentavam uma ocupação consolidada, inclusive com uma rede de infraestrutura estabelecida e sem questões preliminares mais complexas que dificultassem a regularização fundiária.

Neste sentido, as cartas-consulta enfatizavam não só a existência, nas três localidades, de uma rede de serviços básicos razoavelmente estruturada, como também o fato de tais ocupações existirem havia cinco anos ou mais, como eram os casos de Hípica e Morro Lara Vilela. Já em relação à situação fundiária e urbanística, as cartas-consulta ressaltavam igualmente que as áreas nas quais se encontravam as localidades mencionadas, além de demarcadas como zonas especiais de interesse social (ZEIS), eram de domínio do município (casos de Carlos Gomes e Hípica) ou de autarquias federais (caso do Morro Lara Vilela).

Em resumo, é possível observar que a Prefeitura de Niterói, preocupada em cumprir com os requisitos estipulados pela seleção, desejava apresentar esses territórios como assentamentos que teriam certas vantagens para o acolhimento do Programa Papel Passado, tanto pela presença de uma infraestrutura razoável já consolidada como pela capacidade institucional-burocrática da administração pública municipal em lidar com esse tipo de investimento. Assim, em dezembro de 2013 foi publicada a Portaria $n^{0} 575$, que divulgou os projetos selecionados pelo Programa. Entre eles estavam aqueles submetidos pela Prefeitura de Niterói, que celebraria o contrato de repasse com a União por intermédio da Caixa Econômica Federal.

3. Conjunto Habitacional Carlos Gomes e Hípica: contradições do anseio por regularização fundiária

Verificando mais detidamente as informações que são específicas dos locais em que atuamos, percebemos que, em relação ao Conjunto Habitacional Carlos Gomes, localizado no bairro Barretos, uma região importante da cidade, já que está próximo às principais vias de escoamento, como a ponte Rio Niterói e a BR-101, a carta-consulta informava que a área ocupava aproximadamente $1.950 \mathrm{~m}^{2}$, onde residiam dezessete famílias identificadas como de baixa renda - de fato, o conjunto habitacional atendia à tipologia que caracterizava o assentamento. 
Já no termo de referência, documento posterior elaborado para pautar a atuação da empresa que seria futuramente contratada para a execução do projeto de regularização fundiária e urbanística, além das informações aventadas na carta-consulta, descreviam-se as ações e os produtos que deveriam ser entregues pela empresa contratada e se elencavam alguns dados históricos sobre a consolidação do assentamento, tais como a informação de que o Conjunto Habitacional Carlos Gomes fora construído em 2004 pela municipalidade para acolher dezessete famílias desabrigadas em decorrência do deslizamento de pedras ocorrido no Morro do Pires em 2003.

Contrariando a imagem apresentada nas cartas-consulta pela Prefeitura de Niterói sobre sua expertise na condução de projetos de regularização fundiária e urbanística de assentamentos irregulares e na produção de ações que visassem à permanência deles na cidade, a trajetória das moradoras e moradores do Conjunto Habitacional Carlos Gomes denota o intenso protagonismo do poder público na manutenção da precariedade da posse, reiterando justamente o arranjo da tolerância precária.

Em primeiro lugar, o risco de deslizamento na região do Morro do Pires já havia sido reportado pelos moradores às autoridades públicas municipais, e o laudo da Defesa Civil determinava a necessidade de escoramento das pedras, sem que nada tivesse sido feito nesse sentido (MARRA, 2003). Após a ocorrência da tragédia, em 2003, a Prefeitura de Niterói reassentou algumas dessas famílias no Conjunto Habitacional Carlos Gomes, construído sem a observância das normas urbanísticas e fundiárias que constituem a cidade "formal", ou seja, o próprio município não havia aplicado o que o poder público estipulara. Essa forma de atuar do Estado mantém o caráter performativo da norma de definir as margens como informais e mesmo ilegais. A ambiguidade da ação do Estado contra uma norma sua não suscita um reconhecimento passível de ser convertido em direitos universalmente aplicáveis.

Paradoxalmente, foi esse histórico que permitiu ao Conjunto Habitacional Carlos Gomes certas particularidades que, no momento da seleção do Programa Papel Passado, se apresentaram como elementos bastante vantajosos na disputa com outras áreas candidatas, como a tipologia das casas e a existência de uma infraestrutura urbana básica consolidada.

Longe de ser um fator surpresa ou excepcional que fugisse à ciência do Ministério das Cidades, a seleção levava em consideração a existência de hipóteses, como a que aventamos, nas quais a produção de moradias pelo Estado desafiava também a ordem "formal" do espaço urbano. Isso transparece no 
formulário da carta-consulta, cujo campo "tipologia do assentamento" previa a opção "conjunto habitacional”"1.

Em relação ao histórico fundiário, a área em que se localiza o Conjunto Habitacional Carlos Gomes era, ao menos desde a década de 1970, de domínio de entes públicos: pertenceu inicialmente ao antigo Instituto Nacional da Previdência Social (INPS), passou a ser, na sequência, do Banco Nacional de Habitação (BNH) e no fim daquela década encontrava-se sob gestão da Companhia Nacional de Habitação (Cehab/RJ), que, por sua vez, foi responsável pela edificação de uma série de prédios residenciais que atualmente circundam aquela localidade.

Em 2003, a área tornou-se bem público municipal, ao ser gravada como praça. De uso comum do povo, não era mais possível uma destinação diversa daquela pela qual fora constituída. É por essa razão que, quando o espaço em questão foi dedicado à construção do conjunto habitacional, foi necessário realizar sua desafetação ${ }^{12}$ para que fosse transformado em bem dominical do município, o que ocorreu com a promulgação da Lei Municipal n².410/2006 (NITERÓI, 2006). Contudo, como essa desafetação não havia sido levada a registro, transformou-se em um dos entraves para a regularização cartorial.

Somada a essas dificuldades iniciais, a construção das casas não levou em conta a legislação urbanística municipal, de modo que os parâmetros construtivos exigidos para aquela região destoaram dos exibidos pelo Conjunto Habitacional Carlos Gomes. Isso demandaria a demarcação de uma área de especial interesse social (AEIS) para flexibilizar a legislação urbanística. Porém, apesar de a prefeitura ter afirmado na carta-consulta que já havia uma ZEIS, o decreto que constitui a AEIS para o local só foi publicado em agosto de 2016 (NITERÓI, 2016).

Em relação à localidade chamada Hípica, a carta-consulta informava que a área localizada no bairro Charitas tinha aproximadamente $11.950 \mathrm{~m}^{2}$, onde residiam 87 famílias. Diferentemente do Conjunto Habitacional Carlos Gomes, dizia-se que a tipologia característica desse assentamento era favela/ocupação espontânea. Sobre o tempo de ocupação, afirmava-se tratar-se de um assentamento com mais de quinze anos de existência. Essa declaração, embora não negue a informação de que a ocupação datava já da década de 1940, assumida posteriormente no termo de referência, não a explicitava.

11. É interessante notar como muitos conjuntos construídos na cidade do Rio de Janeiro nas décadas de 1960 a 1980 são atualmente considerados favelas: Cidade de Deus, Vila Kennedy, Cidade Alta ou Vila do João.

12. Trata-se da alteração da destinação do bem, de uso comum do povo ou de uso especial, para a categoria de dominicais, desonerando-o do gravame que o vinculava a sua finalidade anterior. 
Ainda que não conste nos dados prestados pela prefeitura, ressaltamos que a Hípica se encontra em um bairro nobre da cidade de Niterói, com vistas para a praia de Charitas e cercado por vários condomínios de classe média e alta. Tais características deixaram pegadas em seu histórico fundiário e, consequentemente, na maneira pela qual as etapas necessárias à regularização fundiária foram conduzidas. A reconstituição desse histórico apontava que a área era de domínio do município de Niterói, já que os registros cartorários davam nota de sua doação, em 2006, por duas construtoras ${ }^{13}$.

A despeito da presunção de veracidade das informações emitidas pelo cartório, enfatizamos mais uma vez que a própria Prefeitura de Niterói, nos documentos fornecidos ao Ministério das Cidades (a carta-consulta e o termo de referência utilizado para guiar os trabalhos desenvolvidos pela empresa contratada) informava, no primeiro caso, que a ocupação teria mais de quinze anos e, no segundo, que esta teria ocorrido ainda na década de 1940. Julgamos importante pontuar também que ali já havia se desenvolvido, em 2008, uma intervenção com fins de regularização urbanística e fundiária. No projeto anterior, termos de concessão de uso para fins de moradia chegaram a ser publicados no Diário Oficial, mas não foram levados a registro.

Reafirmamos que não temos condições, neste texto, de aprofundar a reflexão sobre o papel que outros agentes e interesses desempenham, junto ao Estado, na mobilização das fronteiras que buscam demarcar a informalidade e a formalidade, bem como na reiteração de um tipo de gestão para as áreas de favelas que aqui temos chamado de tolerância precária. Porém, neste caso específico, é interessante notar como agentes que formam o mercado imobiliário estavam altamente implicados na produção de narrativas sobre o bairro de Charitas: ao não incluir a Hípica, formatava-se a ideia de que ela não compunha o passado e, portanto, a história de um espaço que se pretendia elitizado. Na medida em que a doação do terreno, baseada na Lei de Parcelamento do Solo do município (NITERÓI, 1995), não considerou a ocupação da Hípica constituída, no mínimo, havia mais de quinze anos, percebemos como esses arranjos locais, entrelaçados com a norma jurídica, negavam sua existência.

13. Segundo o art. 10 da Lei de Parcelamento do Solo do município de Niterói (Lei $n^{\circ}$ 1.468/1995), nos projetos de parcelamento, na forma de loteamento serão doados ao município $40 \%$ (quarenta por cento) da área total do empreendimento: 5\% para lotes de destinação social e 35\% para uso público, respeitado o mínimo de 5\% para equipamentos comunitários e 10\% para áreas verdes. Já nos projetos de desmembramento de áreas superiores a 10.000,00 $\mathrm{m}^{2}$ (dez mil metros quadrados) deverá ser doada ao município uma área correspondente a 10\% (dez por cento) da área total do terreno, com frente para a via pública, destinada à instalação de equipamentos comunitários e a lotes com destinação social, a juízo do Poder Executivo. 
Esse mesmo mecanismo de apagamento se dava também pela nomeação dada àquela localidade: enquanto a prefeitura, baseada em antigos projetos de loteamento aprovados para a área, insistia em chamá-la de "Hípica”, moradores e moradoras reafirmavam que desde sempre se entenderam como "Charitas", ou seja, naquele contexto específico, "Hípica” evocava uma espécie de distinção entre aquela localidade e o seu entorno, e "Charitas” afirmava justamente o contrário, ou seja, o pertencimento da localidade ao bairro homônimo.

Como vimos, o Programa Papel Passado, desde sua criação, teve dificuldades em obter uma alocação regular de recursos, no entanto, após 2016, a redução foi ainda mais drástica, o que acarretou, em conjunção com outros entraves políticos e burocráticos, a paralisação dos trabalhos, que só retornaram no final daquele mesmo ano. Já em 2017, sob a égide da Lei $n^{\circ}$ 13.465/2017, preparamos a minuta do termo de concessão de uso para fins de moradia (Cuem). Porém, já fora dos projetos, não tínhamos como saber se as assinaturas chegaram a ser colhidas.

\section{Conclusão}

Tanto em Carlos Gomes como em Hípica, foi possível perceber o papel fundamental desempenhado pela Prefeitura de Niterói no desenvolvimento do Programa Papel Passado. Entretanto, ao mesmo tempo, ela parecia agir na contramão dos objetivos ali estipulados: no primeiro caso, vale lembrar, a prefeitura não só construiu um conjunto de casas sem observar as regras urbanísticas e fundiárias, como, ao demorar para efetivar a demarcação de uma AEIS para o local, criou empecilhos para reconhecer essa condição informal por cuja criação era diretamente responsável. Já no segundo caso, deixou inconcluso um projeto anterior que tinha também a finalidade de realizar a regularização fundiária e urbanística do local, além de mostrar dificuldades em reconhecer o histórico daquela ocupação.

Por outro lado, como se manifesta em outros projetos de regularização, não observamos mobilização dos moradores em prol de títulos. Ao contrário, há sempre muitas desconfianças em relação às ações empreendidas pelos poderes públicos e um cálculo de como a formalização pode impactar negativamente arranjos estabelecidos, como entraves burocráticos na venda das casas, maior controle sobre a tipologia e a qualidade das moradias e eventualmente custos tributários. Esse espaço de sombra, com um gradiente bastante variável de aspectos formais/informais, é tacitamente reafirmado por diferentes atores e, mesmo precário, perdura no tempo.

Apesar de essas circunstâncias conjunturais serem importantes para compreender os rumos tomados pelo Programa Papel Passado, com irregularidade de recursos, dificuldades enfrentadas e produzidas pela Prefeitura de Niterói, por exemplo, nossa intenção, com este artigo, não foi interpretá-las através de uma 
lente que aponte para a ineficácia do programa, como sugerem Caldas e Silva (2015), ou para a incapacidade técnico-burocrática da administração pública municipal em levar à frente as ações previstas.

Em uma leitura mais profunda da conjuntura, sugerimos que esses impasses e a própria inconclusão do Programa Papel Passado reverberam a implicação do Estado na produção e na gestão da informalidade que, para os territórios de moradia popular, tem resultado na reiteração do que chamamos aqui de paradigma da tolerância precária, em detrimento da construção de diálogos com as lógicas de produção do espaço nesses territórios.

Para romper com esse arranjo, entendemos ser necessário, primeiro, abandonar a compreensão da informalidade como um elemento a ser combatido. De forma distinta, as políticas podem melhorar as condições de vida dos moradores, dialogando com as práticas ali existentes. Os esforços de regularização devem, portanto, levar em conta a complexidade social das práticas informais. Apoiados na reflexão de Turner (1972, p. 274), compreendemos que as políticas públicas, no que tange aos espaços informais, não devem suprimir nem suplantar as iniciativas locais de produção da cidade, mas sim dialogar com elas. Com base em Alsayyad (2004), pontuamos também que as formas de exceção e tolerância podem estrategicamente ser utilizadas pelos planejadores para mitigar o déficit de moradia e garantir o direito à cidade.

Pensar programas de regularização fundiária com base nessa problematização e em diferentes pontos de partida nos põe inevitavelmente diante de novas reflexões. Por exemplo, torna-se essencial pensar o papel exercido pela lei na gestão da informalidade e na reiteração do paradigma da tolerância precária.

Ademais, verifica-se a necessidade de uma reflexão sobre a acomodação do paradigma da tolerância precária em face dos aspectos neoliberais já evocados por Alsayyad (2004), assim como das particularidades do contexto pós-2018, marcado por um ataque maior às poucas garantias comprometidas com um usufruto mais coletivo das cidades, trazidas pela Constituição de 1988 à custa de longa e intensa atuação de movimentos sociais urbanos. O Programa Casa Verde e Amarela, por exemplo, lançado em 2020 pelo Governo Federal, parece dar centralidade à regularização fundiária de interesse social, porém faz isso convertendo-a em meio para a transformação da terra urbana em ativos financeiros (GUERREIRO; ROLNIK, 2020). Em que medida essa nova lógica desafiará ou se amalgamará com o paradigma da tolerância precária?

Como podemos perceber, há um amplo leque de pontos importantes a serem tratados. Ao analisar os casos de regularização fundiária de Carlos Gomes e Hípica no município de Niterói, o presente artigo procurou instigar a produção de novas reflexões para contextos que se desenham extremamente adversos. 


\section{Referências}

ALMEIDA, G. M. J. A.; SANTOS, R. B. dos; MORETTI, J. A.; GUIMARÃES, I. M. S. S. A política nacional de regularização fundiária: capacidades institucionais dos municípios na implementação do Programa Federal Papel Passado e suas implicações na gestão do território. In: XVII ENCONTRO NACIONAL DA ASSOCIAÇÃO DE PÓS-GRADUAÇÃO E PESQUISA EM PLANEJAMENTO URBANO E REGIONAL. Anais [...] São Paulo: Enanpur, 2017. Tema: Desenvolvimento, crise e resistência: quais os caminhos do Planejamento Urbano e Regional? Disponível em: http://anais.anpur.org.br/index.php/anaisenanpur/ article/view/1644/1623. Acesso em: 29 abr. 2020.

ALSAYYAD, N. Urban informality as a new way of life. In: ROY, A.; ALSAYYAD, N. Urban informality: transnational perspectives from the Middle East, Latin America, and South Asia. Maryland: Lexington Books, 2004.

BIENENSTEIN, R.; BIENENSTEIN, G.; FREIRE, E. H. B.; SOUZA, D. M. M. de. Contextualizando a experiência. In: (org.). Universidade e luta pela moradia. Rio de Janeiro: Consequência, 2017.

BRASIL. Ministério das Cidades. Portaria n 575 de 6 de dezembro de 2013. Diário Oficial da União: seção 1, Brasília, DF, n. 238, p. 73, 9 dez. 2013.

Política Nacional de Desenvolvimento Urbano. Cadernos Mcidades, n. 1, Brasília, 2004. Disponível em: https://erminiamaricato.files.wordpress.com/2016/01/cad-1-politicanacionaldesenvolvimentourbano-texto.pdf. Acesso em 20 abr. 2020.

BRASIL. Lei n 10.257 de 10 de julho de 2001. Regulamenta os arts. 182 e 183 da Constituição Federal, estabelece diretrizes gerais da política urbana e dá outras providências. Diário Oficial da União, Brasília, DF, 11 jul. 2001. Disponível em: http://www.planalto.gov.br/ ccivil_03/leis/leis_2001/l10257.htm. Acesso em: 15 abr. 2020.

. Constituição da República Federativa do Brasil de 1988. Disponível em: http://www. planalto.gov.br/ccivil_03/constituicao/constituicaocompilado.htm. Acesso em: 29 abr. 2020.

CALDAS, D. O. M.; SILVA, M. L. da. Programa Papel Passado: apoio às regularizações fundiárias? Revista de Direitos Sociais e Políticas Públicas, v. 1, n. 2, p. 1-28. jul.-dez. 2015. Disponível em: https://www.indexlaw.org/index.php/revistadspp/article/view/417/pdf. Acesso em: 29 abr. 2020.

CARPINTERO, G. O lugar guardado à regularização fundiária de interesse social na política nacional urbana: o Programa Papel Passado no estado de São Paulo. 2017. 224 f. Dissertação (Mestrado em Planejamento e Gestão do Território) - Universidade Federal do ABC, São Bernardo do Campo, 2017.

CARVALHO, C. S. O Programa Papel Passado. In: ROLNIK, R. (org.). Regularização fundiária sustentável: conceitos e diretrizes. Brasília, DF: Ministério das Cidades, 2007.

CONN, S. The squatters' rights of favelados. In: Ciências Econômicas e Sociais, n. 2, p. 50-142, dez. 1968.

COPANS, R. A regularização fundiária de favelas no estado do Rio de Janeiro. Revista Rio de Janeiro, n. 9, p. 41-53, jan.-abr. 2003. 
DAS, V.; POOLE, D. (org.). Anthropology in the margins of the state. Santa Fe, New Mexico: School of American Research Press, 2004.

FALBO, R. N. Reflexões epistemológicas sobre o direito e a prática da pesquisa jurídica. Revista Direito e Práxis, v. 3, n. 2, 2011.

FOUCAULT, M. Sobre a história da sexualidade. In: Microfísica do poder. Rio de Janeiro: Graal, 1998. p. 243-276.

GONÇALVES, R. S. L'informalité comme une ressource urbaine? Le cas des favelas de Rio de Janeiro. EchoGéo, n. 39, 2017.

. Favelas do Rio de Janeiro. História e direito. Rio de Janeiro: PUC: Pallas, 2013.

GONÇALVES, R. S.; BAUTÈS, N.; MANEIRO, M. Informalidade urbana em questão. O Social em Questão, Ano XXI, n. 42, p. 9-26, 2018.

GUERREIRO, I.; ROLNIK, R. Regularização fundiária Verde e Amarela: endividamento e precariedade. LabCidade, FAU-USP, 8 set. 2020. Disponível em http://www.labcidade. fau.usp.br/regularizacao-fundiaria-verde-e-amarela-endividamento-e-precariedade/. Acesso em: 10 set. 2020.

JACQUOT, S.; SIERRA, A.; TADIE, J. Informalité politique, pouvoirs et envers des espaces urbains. Espace Politique, n. 29, 2016.

JAENISCH, S. T.; XIMENES, L. A. As favelas do Rio de Janeiro e suas camadas de urbanização: vinte anos de políticas de intervenção sobre espaços populares da cidade. XVIII ENCONTRO NACIONAL DA ASSOCIAÇÃO NACIONAL DE PÓS-GRADUAÇÃO E PESQUISA EM PLANEJAMENTO URBANO E REGIONAL, 2019, Natal. Anais [...]. Natal: Enanpur, 2019. Tema: Tempos de/em transformação-utopias. Disponível em: http://anpur.org.br/ xviiienanpur/ anais. Acesso em: 2 dez. 2019.

LIMA SOBRINHO, B. Favelas. Situação jurídica e situação de fato. Revista de Direito da Procuradoria Geral, p. 515-518, 1957.

MACHADO DA SILVA, L. A. "Violência urbana”, segurança pública e favelas - o caso do Rio de Janeiro atual. Caderno CRH, Salvador, v. 23, n. 59, p. 283-300, maio-ago. 2010. Disponível em: https://portalseer.ufba.br/index.php/crh/article/view/19104/12428. Acesso em: 15 abr. 2020.

Prefácio. In: GONÇALVES, R. S. Favelas do Rio de Janeiro. História e direito. Rio de Janeiro: PUC: Pallas, 2013.

MARICATO, E. O Ministério das Cidades e a Política Nacional de Desenvolvimento Urbano. Políticas sociais - acompanhamento e análise, n. 12, 2006. Disponível em: http://www. ipea.gov.br/portal/images/stories/PDFs/politicas_sociais/bps_12_completo.pdf. Acesso em: 8 abr. 2020.

MARRA, L. Promotoria diz que houve "omissão" em deslizamento em Niterói. Folha de S. Paulo. 10 jun. 2003. Cotidiano. Disponível em: https://www1.folha.uol.com.br/folha/cotidiano/ult95u76553.shtml. Acesso em: 29 abr. 2020.

NITERÓI (Município). Decreto $n^{0}$ 12.382/2016. Dispõe sobre a criação e regulamentação da Área de Especial Interesse Social na Rua Carlos Gomes, $n^{0}$ 106, no Bairro Barreto, no Município de Niterói. Disponível em: http://leismunicipa.is/etfus. Acesso em: 10 fev. 2020. 
NITERÓI (Município). Lei $\mathrm{n}^{\circ}$ 2.410, de 21 de dezembro de 2006. Diário Oficial de Niterói: Niterói, 22 dez. 2006. Disponível em: http://leismunicipa.is//rjph. Acesso em: 3 abr.2020.

Lei $\mathrm{n}^{\circ}$ 1.468/1995. Lei de Parcelamento do Solo. Disponível em: https:// urbanismo.niteroi.rj.gov.br/wp-content/uploads/2014/o9/Lei-Municipal-N\%23Uooc2 \%23Uoobo-1468.1995.pdf. Acesso em: 15 mar.2020.

. Plano Diretor de Niterói. Lei $n^{\circ}$ 1.157/1992, alterada pela Lei nº 2.123/2004. Disponível em: http://www.pgm.niteroi.rj.gov.br/leis/lei/Lei_n1157_Plano_Diretor_Alterado_pela_ Lei_2123.pdf. Acesso em: 15 fev. 2020.

ROLNIK, R. Guerra dos lugares: a colonização da terra e da moradia na era das finanças. São Paulo: Boitempo, 2015.

Apresentação geral - curso a distância em regularização fundiária de assentamentos informais urbanos. In: ROLNIK, R. (org.). Regularização fundiária sustentável: conceitos e diretrizes. Brasília: Ministério das Cidades, 2007.

ROY, A. Why India cannot plan its cities: informality, insurgence and the idiom of urbanization. Planning Theory, n. 8, p. 76-87, 2009.

SANTOS, B. de S. Notas sobre a história jurídico-social de Pasárgada. In: SOUTO, C.; FALCÃO, J. (ed.). Sociologia e direito. São Paulo: Livraria Pioneira, 1980. p. 109-117.

TURNER J. Colonização de terras devolutas nos países em desenvolvimento. In: MOYNIHAN, D. O desafio urbano. São Paulo: Cultrix, 1972. p. 262-275. 


\section{Rafael Soares Gonçalves}

Advogado pela Universidade Federal do Rio de Janeiro (UFRJ). Mestre e doutor em História pela Universidade de Paris VII. Pós-doutor em Antropologia pela École des hautes études en sciences sociales (EHESS). Professor associado do Departamento de Serviço Social da PUC-Rio e coordenador do Laboratório de Estudos Urbanos e Socioambientais (LEUS) da mesma instituição. Pesquisador de produtividade do CNPq e Jovem Cientista do Nosso Estado pela Faperj.

Email: rafaelsgoncalves@yahoo.com.br

ORCID: 0000-0001-8887-8931

Contribuição de autoria: conceituação; análise formal; obtenção de financiamento; investigação/pesquisa; escrita - primeira redação; escrita - revisão e edição.

\section{Caroline Rocha dos Santos}

Advogada e mestra pelo Programa de Pós-graduação em Direito da Universidade do Estado do Rio de Janeiro (PPGD/Uerj). Professora do curso de Direito do Centro Universitário Gama e Souza (Unigama).

Email: carolrocha.santos@gmail.com

ORCID: 0000-0002-4188-4426

Contribuição de autoria: conceituação; análise formal; obtenção de financiamento; investigação/pesquisa; escrita - primeira redação; escrita - revisão e edição.

Submissão: 4 de maio de 2020 .

Aprovação: 16 de novembro de 2020.

Como citar: GONÇALVES, R. S.; SANTOS, C. R. dos. Gestão da informalidade urbana e tolerância precária: uma reflexão crítica em torno dos sentidos implicados em projetos de regularização fundiária. Revista brasileira de estudos urbanos e regionais. v. 23, E202103, 2021. DOI 10.22296/2317-1529.rbeur.202103

Artigo licenciado sob Licença Creative Commons CC BY 4.0.

https://creativecommons.org/licenses/by/4.o/deed.pt_BR 